PROGNOSIS

Before the introduction of plasmapheresis, TTP was fatal in more than $80 \%$ of patients within three months. Now about $80 \%$ of the patients treated with exchange plasmapheresis survive the initial episode of TTP. ${ }^{6}$ Thus, early recognition in various clinical settings and prompt, appropriate treatment is of paramount importance.

1 Barton C, Saway AP, Blackburn DW, Sohrab F, Jakes TJ, Alarcon SG. Thrombotic thrombocytopenic purpura in systemic sclerosis. (letter). f R Reumatol 1989; 16: 1400-1.

2 Cooksin S, Krueger LM, Bennet MR. Fulminant thrombotic thrombocytopenic purpura in a patient with the limited form of scleroderma. Successful outcome using plasma exchange. $\mathcal{F}$ Rheumatol 1991; 18: $900-1$.

3 Kahaleh MB Leroy EC. Endothelial cell injury in Kahaleh MB, Leroy EC. Endothelial cell injury in
scleroderma. A protease mechanism. $\mathcal{F}$ Lab Clin Med 1983;

\title{
Anaemia in a child
}

\author{
Semha Berberoğlu
}

A 16-year-old girl was admitted with pallor, fatigue, febrile episodes, and weight loss over a five-month period. On physical examination

\section{Department of \\ Pediatric Oncology, Oncology Hospital, Mesa Koru Sitesi, Orkide Blok 15, 06798 Ankara, Turkey $S$ Berberoğlu}

\begin{tabular}{|lc|}
\hline Laboratory data & \\
\hline - haemoglobin $(\mathrm{g} / \mathrm{dl})$ & \\
- haematocrit $(\%)$ & 6.6 \\
- white blood cells $\left(\times 10^{9} / \mathrm{l}\right)$ & 23.1 \\
- neutrophils $(\%)$ & 1.9 \\
- lymphocytes $(\%)$ & 77 \\
- monocytes $(\%)$ & 20 \\
- reticulocytes $(\%)$ & 3 \\
- platelets $\left(\times 10^{9} / 1\right)$ & 10 \\
- erythrocyte sedimentation rate $(\mathrm{mm} / \mathrm{h})$ & 135 \\
- serum bilirubin $(\mathrm{mg} / \mathrm{dl})$ & 15 \\
$\quad$ total & 1.8 \\
- direct & 0.9 \\
& direct Coombs \\
- haptoglobulin $(\mathrm{mg} / \mathrm{dl})$ & with \\
- bone marrow & IgG \\
\hline
\end{tabular}

Box 1

\section{Final diagnosis}

Thrombotic thrombocytopenic purpura associated with scleroderma.

Keywords: thrombotic thrombocytopenic purpura, scleroderma

4 Lian EC. Thrombotic thrombocytopenic purpura. Annu Rev Med 1988; 39: 203-12.

5 Naild GH. Haemolytic-uraemic syndrome in practice. Lancet 1994; 343: 398-401.

6 Shepard KV, Bukowski RM. The treatment of thrombotic thrombocytopenic purpura with exchange transfusion, plasma infusion and plasma exchange. Semin Hematol plasma infusion she was a thin, markedly pale girl, with a temperature of $39^{\circ} \mathrm{C}$ and scleral jaundice. There was no significant peripheral adenopathy. Her spleen was palpable $12 \mathrm{~cm}$ below the left costal margin and liver was palpable $5 \mathrm{~cm}$ below the right costal margin. Initial laboratory data are given in the box.

On abdominal ultrasonography, hepatosplenomegaly and multiple para-aortic, paracaval, splenic hilar lymphadenopathies were determined. On abdominal computed tomography (CT) there was a nodular pattern in the liver and spleen.

After admission to the hospital, fever up to $39^{\circ} \mathrm{C}$ persisted for 13 days and laparotomy and wedge biopsy from the liver, omentum and abdominal lymph nodes was performed.

\section{Questions}

1 What type is the anaemia?

2 What is the diagnosis?

3 What treatment options are available in the acute phase?

4 What is the long-term strategy in treating this condition? 


\section{Answers}

\section{QUESTION}

Autoimmune haemolytic anaemia. The positive direct Coombs test, haptoglobin less than $30 \mathrm{mg} / \mathrm{dl}$, elevated serum total and direct bilurubin levels, and elevated reticulocyte count support this diagnosis.

\section{QUESTION 2}

Hodgkin's disease. Although any organ may be involved, Hodgkin's disease is characteristically a disease of lymph nodes. Histologic diagnosis is made by the presence of neoplastic reticulum cells (Hodgkin's cells), the most easily recognised form of which is the multinucleated Reed-Sternberg cell.

\section{QUESTION 3}

Corticosteroids with concurrent chemotherapy may be employed initially, reserving splenectomy for later management if necessary.

\section{QUESTION 4}

Staging Hodgkin's disease by determining the anatomic extent of disease provides a rational basis for planning therapy and defining prognosis. According to the Ann Arbor classification, diffuse or disseminated involvement of one or more extra-lymphatic sites with or without lymph node involvement, including all patients with liver or bone marrow involvement, is considered to be stage IV disease. The patient had diffuse involvement of liver, spleen and abdominal lymph nodes, so she was considered to be stage IV disease. Ninety per cent of children and adolescents with Hodgkin's disease can be cured by combinations of chemotherapy and radiation. Devising the therapy with the least long-term side effects without jeopardizing cure is the major challenge in treating young patients. Although the side effects are increased by the use of both modalities, most patients tolerate the combination of radiation and chemotherapy with MOPP (nitrogen mustard, vincristine (oncovine), prednisone, and procarbazine), its variations, or ABVD (adriamycin, bleomycin, vinblastine, and decarbazine). MOPP plus standard dose irradiation is followed by a $1-3 \%$ incidence of acute myelogenous leukemia at a median of 4 years from diagnosis. Substituting ABVD entirely or in part for MOPP, as well as decreasing the dose of radiation given with chemotherapy, may decrease the frequency of secondary leukemia and increase the cure of patients with advanced disease. When MOPP is alternated with ABVD and 2000-2500 cGy radiation therapy, up to $80 \%$ of patients with stages IIIB and IV disease are disease-free after five years.

\section{Discussion}

Immune haemolytic anaemia can be either isoimmune or autoimmune. In the autoimmune form, decreased red cell survival is caused by the action of immunoglobulins, with or without the participation of complement on the red cell membrane. The red cell autoan- tibodies may be of the warm type, the cold type, or the cold-warm Donath-Landsteiner type. Autoimmune haemolytic anaemia may be idiopathic or secondary to a number of conditions listed in box 2 .

Hodgkin's disease arises in a single lymph node or lymph node region. It is a lymphoid malignancy that initially progresses by extending to contiguous lymph node areas. Untreated, it ultimately disseminates and may involve any organ in the body, particularly the spleen, liver, lungs, bones and bone marrow. ${ }^{2}$ Characteristically the first sign of Hodgkin's disease is painless progressive lymph node enlargement. Other signs and symptoms depend on the sites of the nodes involved as they enlarge to cause local tissue compression. About one-third of patients have weight loss, night sweats and fever, so-called "B symptoms". Patients also develop defects in cell-mediated immune function. Both the systemic symptoms and immune defects are rare in patients with localised disease. $^{3}$

\section{AETIOLOGY AND EPIDEMIOLOGY}

The cause is unknown. Incidence is $1-10$ per 100000 population. The bimodal age incidence curve has one peak at 15-35 years of age and another above 50 years of age. In children, the ratio of males to females is 3:1. Epstein-Barr virus has been associated with Hodgkin's disease in epidemiologic and serologic studies.

\section{PATHOLOGY}

The spread of Hodgkin's disease occurs mostly by contiguity from one chain of lymph nodes to another. Diagnosis is based upon the recognition of tumour giant cells (Reed-Sternberg cells) surrounded by benign-appearing host inflammatory cells composed singly or in combination of lymphocytes, histiocytes, granulocytes including eosinophils, plasma cells, and fibroblasts. The Reye classification is currently used most often (box 3). ${ }^{2}$

\section{Causes of immune haemolytic} anaemia $^{1}$

\section{Immune}

- isoimmune (haemolytic disease of the newborn or incompatible blood transfusion)

- autoimmune: IgG only, $C^{\prime} 3$ only; mixed IgG and $C^{\prime} 3$. Idiopathic (warm, cold, or cold-warm (Donath-Landsteiner antibody) type)

Secondary

- infection, viral

- drugs and chemicals

- haematologic disorders: leukemias, lymphomas, lymphoproliferative syndrome, idiopathic thrombocytopenic purpura (Evans syndrome), paroxysmal cold

haemoglobinuria, paroxysmal nocturnal haemoglobinuria

- immunopathic disorders

- tumours: ovarian teratomata, dermoids, thymoma, carcinoma 
CLINICAL MANIFESTATION

The primary nodal site of Hodgkin's disease is above the diaphragm in two-thirds of patients and below in one-third. Teenagers typically have nodular sclerosing Hodgkin's disease $(85 \%)$ with cervical, supraclavicular, or mediastinal involvement. Many have a 'bull-neck' appearance. Unexplained abdominal pain may be caused by enlargement of retroperitoneal nodes. Extension through neural foramina to compress spinal cord, causes para- or quadraparesis. Fever, weight loss or lack of weight gain, and pruritis may occur.

\section{HAEMATOLOGIC FINDINGS}

In localised disease, blood counts are normal. With progression, polymorphonuclear leucocytosis, microcytic hypochromic anaemia, and thrombocytosis are frequent, as is absolute lymphopenia. Multiple nonspecific abnormalities reflecting a generalised inflammatory response occur. Rarely, a Coombspositive haemolytic anaemia, idiopathic thrombocytopenic purpura, or the nephrotic syndrome occurs.

\section{CLINICAL STAGING}

Box 4 shows the internationally accepted staging system for Hodgkin's disease, based on the original classification by Peters and modified at a 1971 Ann Arbor, Michigan, workshop. ${ }^{3}$ Autoimmune haemolytic anaemia in adults is associated with malignancy, particularly of the reticuloendothelial system in $50-60 \%$ of patients. ${ }^{4}$ Eisener and associates reported a $2.7 \%$ incidence of autoimmune haemolytic anaemia in patients having Hodgkin's disease. ${ }^{5}$ In children the presence of autoimmune haemolytic anaemia in Hodgkin's disease has been reported in less than 10 cases with different stages of the disease. ${ }^{6}$ The anaemia usually preceeded the diagnosis, ${ }^{7}$ or heralded a recurrence of the disease. ${ }^{8}$ In all cases, as in ours, the antibody was the warm type of IgG.

\section{THERAPY}

Appropriate treatment in children with Hodgkin's disease depends on the age of the child, stage of disease, and tumour burden. It may involve radiotherapy alone, chemotherapy alone, or most commonly, combined modality treatment. In patients with haemolytic disease, treatment of the haemolytic process is initiated with steroids. ${ }^{6,7,9}$ Our patient was treated with a chemotherapy regimen including steroids. The response of the anaemia was parallel to the disease with stabilisation, further increase in haemoglobin and decrease of the haemolytic components. In our patient, Coombs test

1 Lanzkowsky P. Hemolytic anemia. In: Lanzkowsky P, ed. Manual of pediatric hematology and oncology. New York: Churchill Livingstone, 1995; pp 146-7.

2 Lanzkowsky P. Hodgkin's disease. In: Lanzkowsky P, ed. Manual of pediatric hematology and oncology. New York: Churchill Livingstone, 1995; pp 347-73.

3 Thompson EI. Hodgkin's disease. In: Rudolph MA, ed. Pediatrics. Norwalk, CT: Appleton \& Lange, 1987, pp 1107-10

4 Pirofsky B. Immune hemolytic disease: the autoimmun haemolytic anaemias. Clin Haematol 1975; 4: 167.

5 Eisener E. Coomb's positive hemolytic anemia in Hodgkin's disease. Ann Intern Med 1967; 66: 258.

$6 \mathrm{Chu}$ J. Autoimmune hemolytic anemia in childhood Hodgkin's disease. Am f Pediatr Hematol Oncol 1982; 4: 125-8.

\begin{tabular}{|l|l|}
\hline \multicolumn{2}{|l|}{ Histopathologic classification of } \\
Hodgkin's disease \\
\hline
\end{tabular}

Box 3

\begin{tabular}{|c|c|}
\hline \multicolumn{2}{|c|}{$\begin{array}{l}\text { Clinical staging classification for } \\
\text { Hodgkin's disease } \star^{\star^{3}}\end{array}$} \\
\hline $\begin{array}{l}\text { Stage } \\
\text { I }\end{array}$ & $\begin{array}{l}\text { Criteria for extent of disease } \\
\text { Involvement of a single lymph node } \\
\text { area(I), or a single extralymphatic site } \\
\text { (IE) }\end{array}$ \\
\hline II & $\begin{array}{l}\text { Involvement of two or more lymph node } \\
\text { areas on the same side of the } \\
\text { diaphragm(II), or localised involvement } \\
\text { of one extralymphatic organ or site and } \\
\text { one or more lymph node regions on the } \\
\text { same side of the diaphragm(IIE) }\end{array}$ \\
\hline III & $\begin{array}{l}\text { Involvement of lymph node regions on } \\
\text { both sides of the diaphragm(III), which } \\
\text { may also include localised extralymphatic } \\
\text { involvement(IIIE), splenic } \\
\text { involvement(IIIS), or both(IIIES) }\end{array}$ \\
\hline IV & $\begin{array}{l}\text { Diffuse or disseminated involvement of } \\
\text { one or more extralymphatic sites with or } \\
\text { without lymph node involvement, } \\
\text { including all patients with liver or bone } \\
\text { marrow involvement }\end{array}$ \\
\hline \multicolumn{2}{|c|}{$\begin{array}{l}\text { ^All stages are subclassified A or B to indicate } \\
\text { absence or presence of unexplained fever, night } \\
\text { sweats, or unexplained loss of } 10 \% \text { or more of } \\
\text { body weight in the preceeding six months. }\end{array}$} \\
\hline
\end{tabular}

\section{Box 4}

became negative in three months, although disease was at an advanced stage. It is reported that autoimmune haemolytic anaemia in children does not imply bad prognosis and its treatment is that of the basic disease. ${ }^{10}$ In our patient treatment of the basic disease has resulted in the resolution of the haemolytic process but enough time has not passed to allow us to judge the prognosis. In conclusion, Hodgkin's disease and autoimmune haemolytic anaemia is an uncommon entity in childhood. Although rare, treatment is that of the basic disease and the prognosis is not necessarily bad.

\section{Final diagnosis}

Autoimmune haemolytic anaemia secondary to Hodgkin's disease.

Keywords: Hodgkin's disease, autoimmune haemolytic anaemia, childhood

7 May R, Bryan J. Autoimmune hemolytic anemia and Hodgkin's disease. $\mathcal{A}$ Pediatrics 1976; 89: 428-30.

8 Brice P, Marolleau J, D'agay M, Epardeau B, Gisselbrech C. Autoimmune hemolytic anemia disclosing Hodgkin's disease associated with Castleman's disease. Nouv Rev F Hematol 1991; 33: 273-4.

9 McElfresh A, Waeltermann B. Autoimmune hemolytic anemia as a presenting manifestation of Hodgkin's disease. $\mathcal{f}$ Pediatrics 1976; 89: 429-30.

10 Kalmanti M, Polychronopoulou S. Autoimmune hemolytic anemia as an initial symptom in childhood Hodgkin's disease. Pediatr Hematol Oncol 1992; 9: 393-5. 